\title{
Saturated fatty acids entrap PDX1 in stress granules and impede islet beta cell function
}

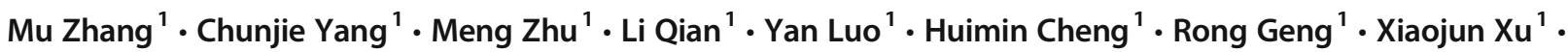 \\ Cheng Qian ${ }^{2} \cdot$ Yu Liu ${ }^{1}$
}

Received: 14 September 2020 / Accepted: 16 November 2020 / Published online: 11 February 2021

(C) The Author(s), under exclusive licence to Springer-Verlag GmbH, DE part of Springer Nature 2021

\begin{abstract}
Aims/hypothesis Failure of pancreatic and duodenal homeobox factor 1 (PDX1) to localise in the nucleus of islet beta cells under high-fat diet (HFD) conditions may be an early functional defect that contributes to beta cell failure in type 2 diabetes; however, the mechanism of PDX1 intracellular mislocalisation is unclear. Stress granules (SGs) are membrane-less cytoplasmic structures formed under stress that impair nucleocytoplasmic transport by sequestering nucleocytoplasmic transport factors and components of the nuclear pore complex. In this study, we investigated the stimulators that trigger SG formation in islet beta cells and the effects of SGs on PDX1 localisation and beta cell function.

Methods The effect of palmitic acid (PA) on nucleocytoplasmic transport was investigated by using two reporters, S-tdTomato and S-GFP. SG assembly in rat insulinoma cell line INS1 cells, human islets under PA stress, and the pancreas of diet-induced obese mice was analysed using immunofluorescence and immunoblotting. SG protein components were identified through mass spectrometry. SG formation was blocked by specific inhibitors or genetic deletion of essential SG proteins, and then PDX1 localisation and beta cell function were investigated in vitro and in vivo.

Results We showed that saturated fatty acids (SFAs) are endogenous stressors that disrupted nucleocytoplasmic transport and stimulated SG formation in pancreatic beta cells. Using mass spectrometry approaches, we revealed that several nucleocytoplasmic transport factors and PDX1 were localised to SGs after SFA treatment, which inhibited glucose-induced insulin secretion. Furthermore, we found that SFAs induced SG formation in a phosphoinositide 3-kinase (PI3K)/eukaryotic translation initiation factor $2 \alpha$ (EIF2 $\alpha$ ) dependent manner. Disruption of SG assembly by PI3K/EIF2 $\alpha$ inhibitors or genetic deletion of $\mathrm{T}$ cell restricted intracellular antigen 1 (TIA1) in pancreatic beta cells effectively suppressed PA-induced PDX1 mislocalisation and ameliorated HFD-mediated beta cell dysfunction.

Conclusions/interpretation Our findings suggest a link between SG formation and beta cell dysfunction in the presence of SFAs. Preventing SG formation may be a potential therapeutic strategy for treating obesity and type 2 diabetes.
\end{abstract}

Keywords Glucose-stimulated insulin secretion $\cdot$ Pancreatic and duodenal homeobox factor $1 \cdot$ Saturated fatty acids $\cdot$ Stress granules · Type 2 diabetes

Yu Liu

drliuyu@njmu.edu.cn

Cheng Qian

ctsien@163.com

Xiaojun Xu

xiaojunxu@cpu.edu.cn

1 Department of Endocrinology, Sir Run Run Hospital, Nanjing Medical University, Nanjing, China

2 Department of Nephrology, Sir Run Run Hospital, Nanjing Medical University, Nanjing, China

\section{Abbreviations}

ALS Amyotrophic lateral sclerosis

EIF $2 \alpha \quad$ Eukaryotic translation initiation factor $2 \alpha$

ER Endoplasmic reticulum

G3BP1 GAP SH3 binding protein 1

GSIS Glucose-stimulated insulin secretion

HFD High-fat diet

ISRIB Integrated stress response inhibitor

NES Nuclear export sequence

NLS Nuclear localisation signal

PA Palmitic acid

PDX1 Pancreatic and duodenal homeobox factor 1 


\section{Research in context}

\section{What is already known about this subject?}

- Failure of pancreatic and duodenal homeobox factor 1 (PDX1) to localise in the nucleus of islet beta cells under high-fat diet conditions may be an early functional defect that contributes to beta cell failure in type 2 diabetes

- Stress granules (SGs) impair nucleocytoplasmic transport by sequestering nucleocytoplasmic transport factors and components of the nuclear pore complex

\section{What is the key question?}

- Does SG formation contribute to PDX1 mislocalisation and beta cell dysfunction under saturated fatty acid (SFA) stress conditions?

What are the new findings?

- SFAs inhibit glucose-induced insulin secretion by disrupting nucleocytoplasmic transport and sequestering PDX1 in SGs

- SFAs induce SG assembly in islet beta cells in a PI3K/EIF2a-dependent manner

- Preventing SG formation rescues SFA-induced beta cell dysfunction

\section{How might this impact on clinical practice in the foreseeable future?}

- Our findings suggest a link between SG formation and beta cell dysfunction induced by SFAs. Modulating SG formation may be a potential therapeutic strategy for obesity and type 2 diabetes. The effects of SG inhibitors on type 2 diabetes need to be explored in future studies

PI3K Phosphoinositide 3-kinase

PIC Stalled (preinitiation) translation complex

RAN Ran GTPase

SFA Saturated fatty acid

SG Stress granule

siRNA Small interfering RNA

TIA1 T cell restricted intracellular antigen 1

TIAL1 TIA1 cytotoxic granule associated RNA binding protein like 1

WCL Whole cell lysate

WT Wild-type

\section{Introduction}

Progressive degeneration of pancreatic islet beta cell function is considered to be the central pathophysiological mechanism of type 2 diabetes [1]. Obesity is the dominant risk factor for type 2 diabetes [2]. The relentless decline in beta cell function is attributed to elevated levels of circulating fatty acids associated with obesity $[3,4]$. Long-chain saturated fatty acids (SFAs) that contain more than 12 carbons are toxic to beta cells $[4,5]$. Short term administration of SFAs induces insulin secretion [6]; however, prolonged exposure to SFAs triggers ceramide accumulation [7], reactive oxygen species production [8] and endoplasmic reticulum (ER) stress [9], and impedes glucose-stimulated insulin secretion (GSIS), impairs insulin gene expression and increases apoptosis $[10,11]$ in isolated islets or beta cell lines. However, the basis of SFAinduced beta cell dysfunction remains unclear.

The transcription factor pancreatic and duodenal homeobox factor 1 (PDX1) binds to the A3 element of the insulin gene, and is crucial for pancreatic development and normal function. PDX1 deficiency in animals leads to pancreatic agenesis [12]. Heterozygosity for $P D X 1$ mutation is related to impaired glucose tolerance and reduced GSIS, triggering maturity-onset diabetes of the young (MODY) [13-15]. It has been reported that prolonged exposure of isolated rat islets to palmitic acid (PA) [10], intralipid infusion [16] or high-fat diet (HFD) [17] blocked the stimulatory effects of glucose on PDX1 nuclear localisation, thereby preventing PDX1 from binding to the endogenous gene promoter and inhibiting the transcription of genes involved in GSIS. Failure of PDX1 to localise in the nucleus in the presence of SFAs may be an early functional defect that contributes to beta cell failure in type 2 diabetes. However, the main reason for PA-induced PDX1 mislocalisation in beta cells is still unclear.

Stress granules (SGs) are membrane-less cytoplasmic structures formed by phase separation. SGs comprise abundant untranslated mRNAs, mRNA-binding proteins, ribonucleoproteins and translation initiation factors [18]. They are formed when translation initiation is inhibited during stress responses such as oxidative stress, ER stress and viral infection, and modulate the stress response [19, 20]. Persistent or aberrant SG formation contributes to neurodegenerative diseases including amyotrophic lateral sclerosis (ALS) [21], 
frontal temporal lobar dementia (FTLD) [22], and cancers [23]. Recent research has shown that many nucleocytoplasmic transport factors and components of the nuclear pore complex are localised to SGs after exposure to stressors, leading to impaired nucleocytoplasmic transport. Inhibition of SG assembly by inhibitors or knockdown of essential components of SGs suppressed nucleocytoplasmic transport defects and neurodegeneration in animal models [24]. Currently, the physiological or pathological stimulators that trigger SG formation in the pancreas remain unexplored. The aim of our study was to investigate the stimulators that trigger SG formation in islet beta cells and the effects of SGs on PDX1 localisation and beta cell function.

\section{Methods}

Materials Anti-PDX1 (catalogue no. \#5679), anti-phosphoPI3 kinase p85 (Tyr458)/p55 (Tyr199) (catalogue no. \#17366) antibodies and DAPI (catalogue no. \#4083) were purchased from Cell Signaling Technology (Danvers, MA, USA). Anti-GAP SH3 binding protein 1 (G3BP1) (catalogue no. 13057-2-AP, 66486-1-Ig), anti-T cell restricted intracellular antigen 1 (TIA1) (catalogue no. 12133-2-AP), anti-ataxin2 (catalogue no. 21776-1-AP), anti-importin $\alpha 6$ (catalogue no. 13963-1-AP), anti-exportin1 (catalogue no. 66763-1-Ig) and anti-Ran GTPase (RAN) (catalogue no. 10469-1-AP) antibodies were purchased from Proteintech (Wuhan, China). Antiphospho Akt (Ser473) (catalogue no. AA329), anti-phospho Akt (Thr803) (catalogue no. AA331), anti-phosphoeukaryotic translation initiation factor $2 \alpha$ (EIF2 $\alpha)$ (Ser51) (catalogue no. AF1237), anti-EIF $2 \alpha$ (catalogue no. AF6771), anti- $\beta$-actin (catalogue no. AF5001), anti-GAPDH (catalogue no. AF0006), goat anti-mouse IgG (catalogue no. A0216) and goat anti-rabbit IgG (catalogue no. A0208) antibodies were purchased from Beyotime Biotechnology (Shanghai, China). Mouse anti-rabbit IgG LCS (catalogue no. A25022) antibody was purchased from Abbkine (Wuhan, China). Alexa Fluor 594 conjugated anti-PDX1 (catalogue no. sc-390792 AF594) antibody was purchased from Santa Cruz Biotechnology (Dallas, TX, USA). Alexa Fluor 488 AffiniPure donkey anti-rabbit IgG (code no. 711545-152), Cy3 AffiniPure donkey anti-rabbit IgG (code no. 711-165-152) and Cy3 AffiniPure donkey anti-Mouse IgG (code no. 715-165-151) antibodies were purchased from Jackson ImmunoResearch (West Grove, PA, USA). Integrated stress response inhibitor (ISRIB; HY-12495) and buparlisib (HY-70063) were purchased from MedChemExpress (Monmouth Junction, NJ, USA). PA (P1145) was purchased from TCI (Shanghai, China). D (+) glucose (G7021) was purchased from Sigma-Aldrich (St Louis, MO, USA).
Cell culture and treatments Rat insulinoma cell line INS1 cells were kindly provided by J. Zhang (The Second Xiangya Hospital of Central South University, China). Cells are verified to be of rat origin and negative for inter-species contamination from mouse or human. Mycoplasma was tested as negative using Mycoplasma PCR detection kit (Beyotime Biotechnology). INS1 cells were grown in 5\% $\mathrm{CO}_{2}$ and $95 \%$ air at $37^{\circ} \mathrm{C}$ in RPMI-1640 medium (KeyGen, Nanjing, China) containing $11.2 \mathrm{mmol} / \mathrm{l}$ glucose and supplemented with $10 \%$ FBS (GE Healthcare Hyclone, Chicago, IL, USA), $1 \mathrm{mmol} / 1$ pyruvate, $10 \mathrm{mmol} / 1$ HEPES (Gibco, Life Technologies, Carlsbad, CA, USA), $100 \mathrm{U} / \mathrm{ml}$ penicillin, and $100 \mu \mathrm{g} / \mathrm{ml}$ streptomycin, $50 \mu \mathrm{mol} / 1$ 2-mercaptoethanol (Sigma-Aldrich). PA was dissolved in absolute ethanol to make a $100 \mathrm{mmol} / \mathrm{l}$ stock solution. The PA stock solution was mixed with $1 \%$ fatty acid-free BSA (Gibco, Life Technologies) (in serumfree culture medium) to a final concentration of $0.4 \mathrm{mmol} / \mathrm{l}$ and incubated at $37^{\circ} \mathrm{C}$ for $1 \mathrm{~h}$ to prepare BSA-conjugated PA solution. All cell experiments were performed with INS1 cells between the 4 th and 15 th passages.

Animals and treatments B6/JGpt-Tial $1^{\mathrm{em} 1 \mathrm{Cflox}} / \mathrm{Gpt}\left(\right.$ Tial ${ }^{f / 4}$ ) mice (Strain number T036619, GemPharmatech, Nanjing, China; http://order.gempharmatech.com/strain/index? keyword=T036619) were generated using the CRISPR/Cas9 method. In brief, single guide RNA (sgRNA) was transcribed in vitro to construct the donor vector, and then Cas9, sgRNA and the donor were microinjected into the fertilised eggs of C57BL/6J mice. Fertilised eggs were transplanted to obtain positive F0 mice. A stable F1 generation was obtained by mating positive $\mathrm{F} 0$ generation mice with $\mathrm{C} 57 \mathrm{BL} / 6 \mathrm{~J}$ mice. B6.Cg- $\mathrm{Tg}($ Ins 2-cre) $25 \mathrm{Mgn} / \mathrm{J}$ (Ins2Cre) mice (Stock number 003573, The Jackson Laboratory, Bar Harbor, ME, USA; https://www.jax.org/strain/003573) mice were kindly provided by X. Han (Department of Biochemistry and Molecular Biology, Nanjing Medical University, China). The breeding scheme is shown in electronic supplementary material (ESM) Fig.1. Tial ${ }^{f / f}$ mice were crossed with Ins2Cre mice to generate beta cell-specific Tial-knockout $\left(\right.$ Tial ${ }^{f / f}$; Cre, betaTIA1-KO) mice. Tia $1^{f / f}$ wild-type (WT) littermates were used as control. All mice were kept on the C57BL/6 background. Animals were housed under standard conditions at $25^{\circ} \mathrm{C}$ with a $12 \mathrm{~h} / 12 \mathrm{~h}$ dark/light cycle, with food and water freely available. All experiments were performed in male animals. All experiments and animal care were conducted in accordance with the Provision and General Recommendation of the Chinese Experimental Animals Administration Legislation and were approved by the Science and Technology Department of Jiangsu Province (license number: SYXK (SU) 2016-0011). To generate an HFD-induced type 2 diabetes model, eight-week-old male mice (22-25 g) were randomly separated into normal chow group (D10001, Research Diets, New Brunswick, NJ, USA) 
and an HFD group (60\% energy from fat, D12492, Research Diets.) for 10 weeks.

\section{Human pancreatic sample collection and islet isolation} Human islets were obtained from the pancreas of two nondiabetic donors undergoing pancreatectomy for intraductal papillary mucinous neoplasm with the approval of the Ethics Committee. Islets were isolated by collagenase digestion $(0.5 \mathrm{mg} / \mathrm{ml}$, type $\mathrm{V}$, Sigma-Aldrich) as described previously [25]. All islets were incubated overnight at $37^{\circ} \mathrm{C}\left(5 \% \mathrm{CO}_{2}\right)$ prior to experiments. A human islet checklist is provided in the ESM. All experiments and methods using human islets were carried out in accordance with the Declaration of Helsinki and approved by the Nanjing Medical University Ethics Committee (No. 2017-SR-003).

Glucose tolerance tests IPGTT was performed on mice fasted overnight with free access to water. Mice were i.p. administrated with $2 \mathrm{~g} / \mathrm{kg}$ glucose (Sigma-Aldrich). Glucose levels were measured from tail blood at 15, 30, 60 and 120 min after the glucose injection. The AUC was calculated to quantify the IPGTT results.

Pancreatic insulin content assay Pancreatic insulin content was determined by acid ethanol extraction as previously described [26]. The insulin levels in neutralised pancreatic extracts were determined by mouse insulin ELISA kit (CUSABIO, Wuhan, China). Protein concentrations were measured by BCA assay kit (Beyotime Biotechnology).

GSIS assay GSIS assay was performed as previously described [27]. The medium of the INS1 cells or isolated islets was changed to Krebs-Ringer bicarbonate HEPES (KRBH) buffer for $2 \mathrm{~h}$, followed by incubation in KRBH buffer containing $2.8 \mathrm{mmol} / 1$ of glucose or $16.7 \mathrm{mmol} / 1$ of glucose for $30 \mathrm{~min}$. The insulin levels in the medium were measured using an ELISA kit (CUSABIO, Wuhan, China).

Immunoblotting and co-immunoprecipitation assay SGs were separated as described previously [28]. Cells were collected and re-suspended in lysis buffer $(50 \mathrm{mmol} / \mathrm{l}$ Tris $\mathrm{HCl} \mathrm{pH} \mathrm{7.4,} 100 \mathrm{mmol} / \mathrm{l}$ potassium acetate, $2 \mathrm{mmol} / \mathrm{l}$ magnesium acetate, $0.5 \mathrm{mmol} / \mathrm{l}$ dithiothreitol (DTT), $50 \mu \mathrm{g} / \mathrm{ml}$ heparin, $0.5 \%$ NP40) supplemented with protease inhibitor cocktail (cOmplete, Roche, Germany), and lysed by passing them five times through a $25 \mathrm{G} 5 / 8$ needle, followed by centrifugation at $1000 \times g$ for $5 \mathrm{~min}$ to pellet cell debris. The supernatant was collected as a whole cell lysate (WCL) and protein concentration was determined with the BCA assay. Equal amounts of proteins were further spun at $18000 \times \mathrm{g}$ for $20 \mathrm{~min}$. The pellet containing SGs (P18000) and the supernatant were collected for western blot analysis. Nuclear proteins and cytosolic proteins were obtained using the NE-PER kit
(Thermo Fisher Scientific, Waltham, MA, USA) containing protease inhibitors (Roche).

For co-immunoprecipitation assays, cell lysates were incubated with PDX1 antibody (1:50) overnight at $4^{\circ} \mathrm{C}$, and then with protein $\mathrm{A} / \mathrm{G}$ plus agarose beads $(20 \mu \mathrm{l} / \mathrm{sample})$ for $1 \mathrm{~h}$ at $4{ }^{\circ} \mathrm{C}$. Immunoprecipitants were collected by centrifugation and washed four times with lysis buffer, and then the beads were precipitated through centrifugation and re-suspended in electrophoresis sample buffer.

For immunoblotting, protein samples were mixed with electrophoresis sample buffer and heated at $98^{\circ} \mathrm{C}$ for $10 \mathrm{~min}$. The samples were run on $10 \%$ or $15 \%$ SDS-PAGE and transferred onto PVDF membranes. Membranes were blocked with $5 \%$ non-fat milk (BD Difco, Detroit, MI, USA) for $1 \mathrm{~h}$ at room temperature and incubated with primary antibodies overnight at $4{ }^{\circ} \mathrm{C}$, washed, and then incubated with horseradish peroxidase (HRP)-conjugated secondary antibodies for $2 \mathrm{~h}$ at room temperature. All primary antibodies were used at 1:1000 dilution. The secondary antibodies were used at 1:5000 dilution. The primary antibodies were diluted in TBST with 5\% BSA, and the secondary antibodies were diluted in TBST. Signals were detected using Immobilon Western HRP substrate (Millipore, Billerica, MA, USA). Protein levels were analysed using a ChemiDoc XRS+ imaging system (Bio-Rad, Hercules, CA, USA) and Image J software (NIH, Bethesda, MD, USA).

For isobaric tags for relative and absolute quantification (iTRAQ)-based proteomics analysis, the P18000 samples were re-suspended in lysis buffer and incubated with G3BP1 antibody $(2 \mu \mathrm{g})$ at $4{ }^{\circ} \mathrm{C}$ overnight, followed by incubation with protein $\mathrm{A} / \mathrm{G}$ plus agarose beads $(20 \mu \mathrm{l} / \mathrm{sample})$ for $1 \mathrm{~h}$ at $4^{\circ} \mathrm{C}$. Immunoprecipitants were collected and washed, and then the beads were precipitated by centrifugation and re-suspended in electrophoresis sample buffer. The samples were run on $10 \%$ SDS-PAGE. Gels were digested with trypsin overnight. The peptide samples were labelled by an iTRAQ labelling kit (Sigma-Aldrich) according to the manufacturer's protocol. The labelled peptides were fractionated on a $\mathrm{C} 18$ column using an HPLC system. The peptide fractions were analysed using a TripleTOF 5600+ LC-MS/MS system (AB Sciex, Redwood City, CA, USA).

Plasmids and siRNA transfection S-tdTomato (Lentiviral-StdTomato) was a gift from J. Rothstein (Department of Neurology, School of Medicine, Johns Hopkins University, Baltimore, MD, USA) (Addgene plasmid \#112579) [29]. The S-GFP plasmid was a kind gift from F. U. Hartl (Department of Cellular Biochemistry, the Max Planck Institute of Biochemistry, Germany). siRNAs targeting rat G3bpl (GGGCGUCUGUGACUAGUAATT) and Tia 1 (CCAAUUGGGCCACACGUAATT) were purchased from GenePharma (Shanghai, China). Scrambled small interfering RNA (siRNA) (UUCUCCGAACGUGUCACGUTT) was 
Fig. 1 SFAs disrupted nucleocytoplasmic transport and stimulated SG formation in pancreatic beta cells. $(\mathbf{a}, \mathbf{b})$ INS1 cells expressing S-tdTomato (a) or S-GFP (b) were treated with PA $(0.4 \mathrm{mmol} / \mathrm{l})$ or glucose ( $33.3 \mathrm{mmol} / \mathrm{l})$ for $16 \mathrm{~h}$, and then were stained with anti-G3BP1 antibody and DAPI. Scale bar, $5 \mu \mathrm{m}$. (c, d) INS1 cells were treated with $\mathrm{NaAsO}_{2}(0.5 \mathrm{mmol} / \mathrm{l})$ for $0.5 \mathrm{~h}$, or with PA $(0.4 \mathrm{mmol} / \mathrm{l})$ or glucose $(33.3 \mathrm{mmol} / \mathrm{l})$ for $16 \mathrm{~h}$ (c). Islets isolated from human pancreases were treated with PA $(0.4 \mathrm{mmol} / \mathrm{l})$ for $16 \mathrm{~h}(\mathbf{d})$. Cells were collected and WCL was prepared and further separated into detergent soluble fraction (supernatant after $18,000 \times g, \mathrm{~S}$ ) and insoluble fractions (SGenriched fraction, P18000). All samples were analysed using immunoblotting for ataxin2, G3BP1 and TIA1. Data are presented as mean $\pm \mathrm{SD}$. $* p<0.05, * * p<0.01$, *** $p<0.001$. (a) $n=21-26$; (b) $n=21-29 ;$ (c, d) $n=3$. Ctrl, Control; Glu, glucose; N/W, nucleus/whole cell; P18000, pellet from $18,000 \times g ; \mathrm{S}$, supernatant after $18,000 \times g$ a
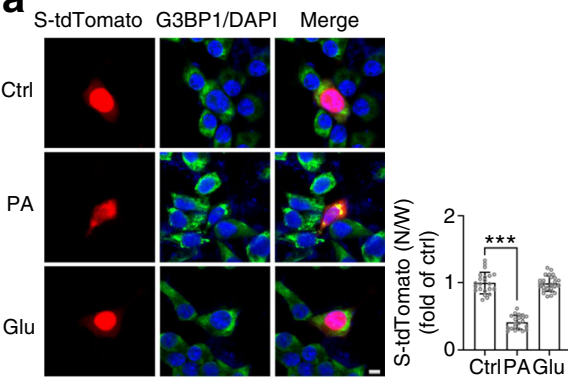

C

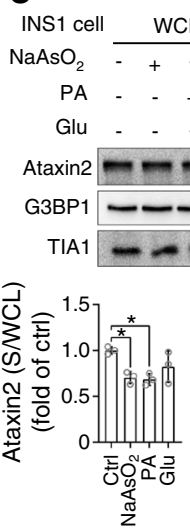

WCL

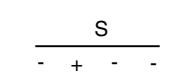

P18000
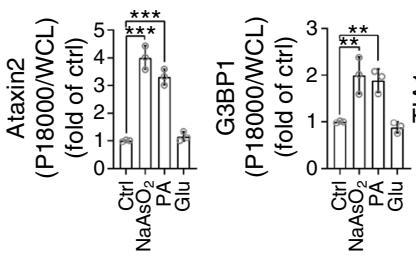
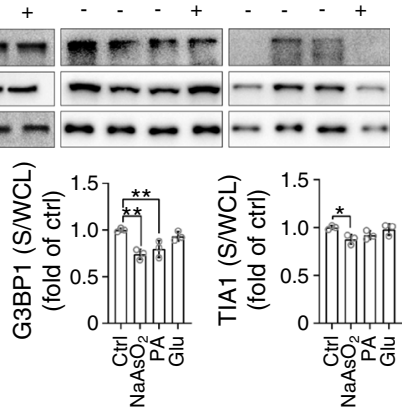

离

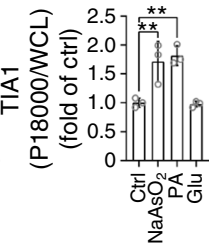

b

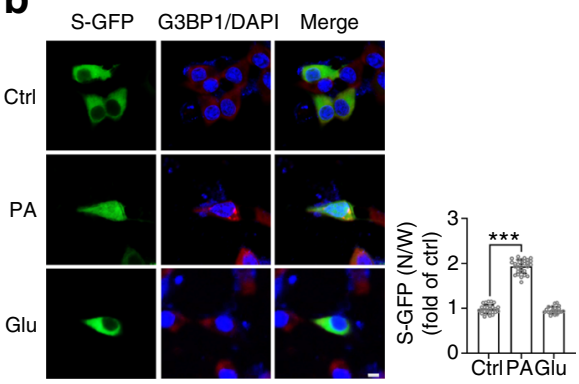

d

Human islets
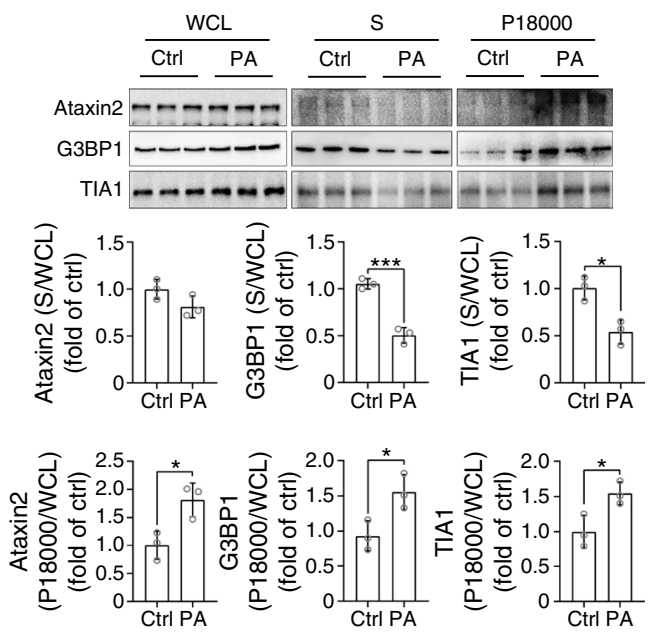

used as control. Transient transfections were performed using Lipofectamine 3000 or RNAi Max (Invitrogen, Carlsbad, CA, USA) according to the manufacturer's instructions.

Immunofluorescence assay INS1 cells or frozen tissue slides were fixed with $4 \%$ paraformaldehyde and blocked in blocking buffer (PBS, 0.3\% Triton X-100, 5\% normal donkey serum), and then incubated with the indicated primary antibodies at $4^{\circ} \mathrm{C}$ overnight. Cells or tissue slides were then incubated with Alexa Fluor 488 or Cy3 AffiniPure secondary antibodies for $1 \mathrm{~h}$ at room temperature. All primary and secondary antibodies were diluted in antibody dilution buffer (PBS, $0.3 \%$ Triton $\mathrm{X}-100,1 \% \mathrm{BSA})$. The primary antibodies were used at 1:300 dilution, except for Alexa Fluor 594 conjugated anti-PDX1 antibody that was used at 1:50 dilution. The secondary antibodies were used at 1:500 dilution. Cells or tissue slides were subsequently incubated with DAPI (Thermo Fisher Scientific) for 15 min and washed with PBS before being mounted with fluorescence mounting medium (KeyGen, Nanjing, China). Immunofluorescence was visualised and captured under a confocal microscope (LSM 700 , Zeiss, Göttingen, Germany). Three to ten fields of views were randomly selected for quantification analysis.
Statistical analysis All data are expressed as the mean \pm SD. The significance of differences between two groups was determined using Student's unpaired $t$ test. Comparisons between groups were performed using one-way ANOVA (Tukey's multiple comparisons test). Differences with $p<0.05$ were considered to be statistically significant. All experimenters were blind to group assignments and outcome assessment, except for the type of diet. Mice with accidental death were excluded from data statistics.

\section{Results}

PA disrupts nucleocytoplasmic transport and induces SG assembly It has been suggested that long-chain SFAs such as PA (C16:0), have been implicated to induce beta cell stress [30]. To determine whether such stress affects nucleocytoplasmic transport, two reporters, S-tdTomato and S-GFP, were used. S-tdTomato contains a canonical nuclear localisation signal (NLS) and a nuclear export sequence (NES) to shuttle between the cytoplasm and nucleus [29]. SGFP also carries NES and NLS signals, but in a different order than S-tdTomato [31]. In the absence of stress, S-tdTomato 
Fig. 2 SFAs sequester PDX1 in SGs. (a) Distribution of the identified proteins according to molecular function. (b) INS1 cells were treated with PA $(0.4 \mathrm{mmol} / \mathrm{l})$ for $16 \mathrm{~h}$ and then stained with anti-TIA1 antibody (green), antiPDX1 antibody (red) and DAPI (blue). Short arrows indicate colocalisation. Scale bar, $5 \mu \mathrm{m}$. On the right, line scans are shown of the images of a cell co-stained for G3BP1 and PDX1 at the position depicted by the long arrow. (c, d) PDX1 levels in the SG-enriched fraction separated from INS1 cells (c) or human islets (d), as well as ataxin2 and G3BP1 in (c) and TIA1 in both. (e, f) Coimmunoprecipitation of SG markers, including ataxin2, G3BP1 and TIA1 with PDX1 from INS1 cells treated with PA for $16 \mathrm{~h}(\mathbf{e})$, or from mouse pancreatic tissues after HFD for 10 weeks (f). Data are presented as mean \pm SD. $* p<0.05$, $* * p<0.01, * * * p<0.001$. (c-e) $n=3$; (f) $n=6$. Ctrl, control; IP, immunoprecipitate; $\mathrm{NC}$, normal chow; P18000, pellet from $18,000 \times g$; ROI, region of interest; $\mathrm{S}$, supernatant after $18,000 \times g$ a
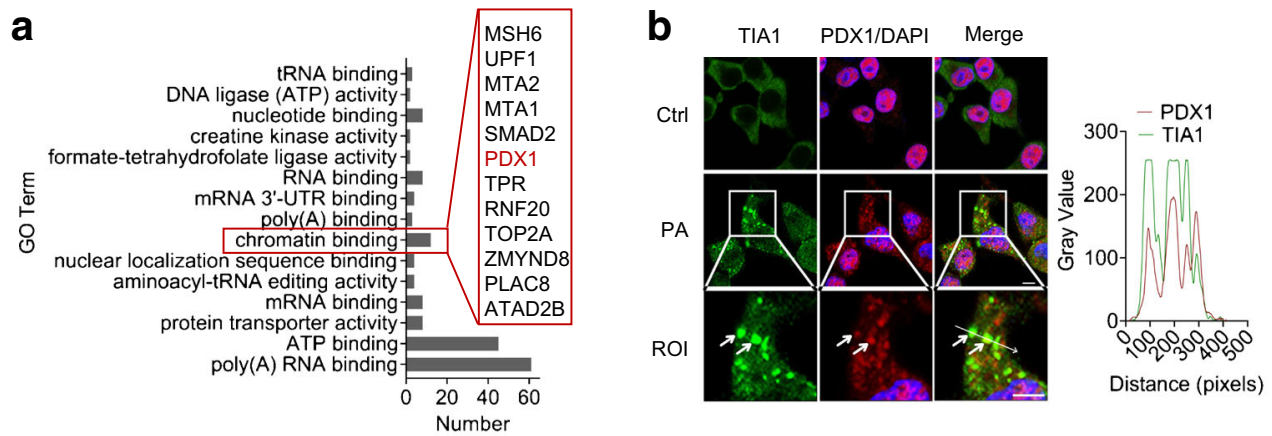
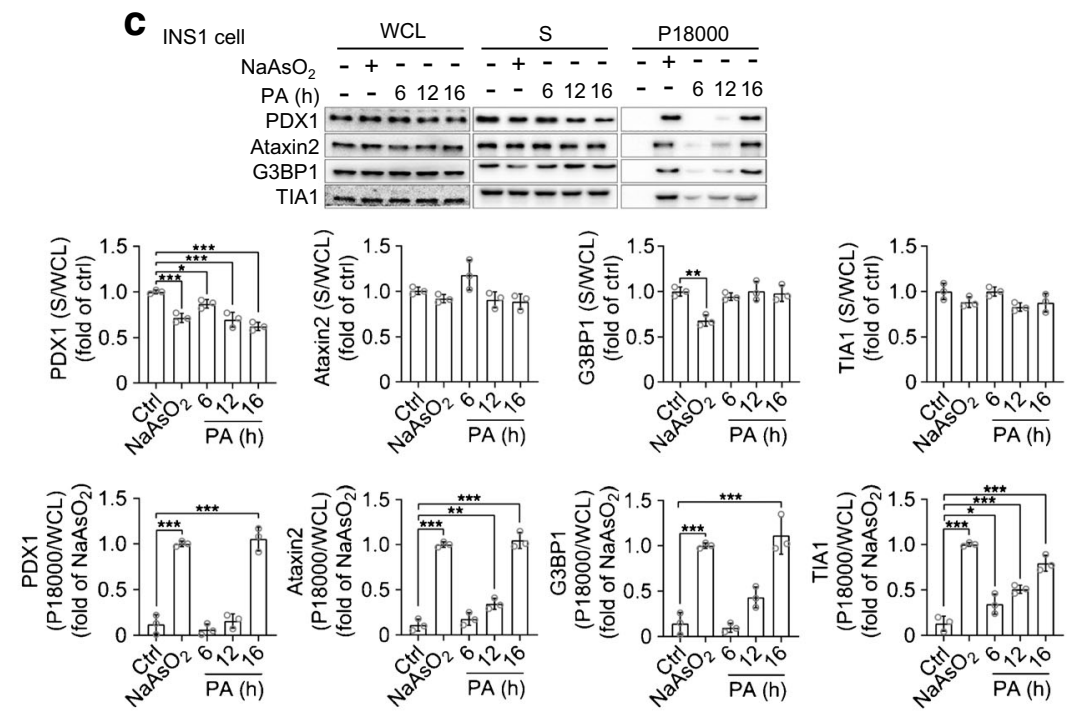

d

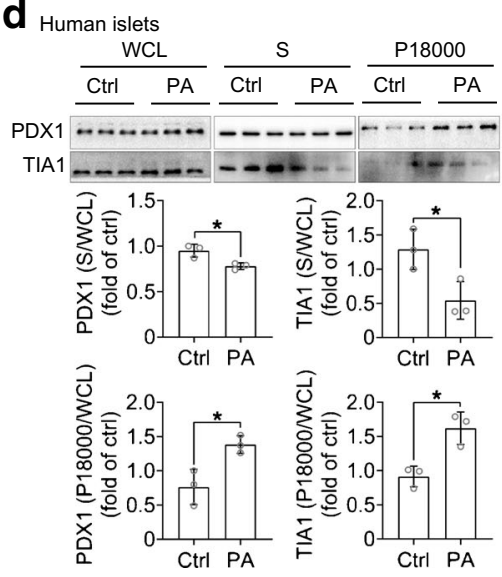

e

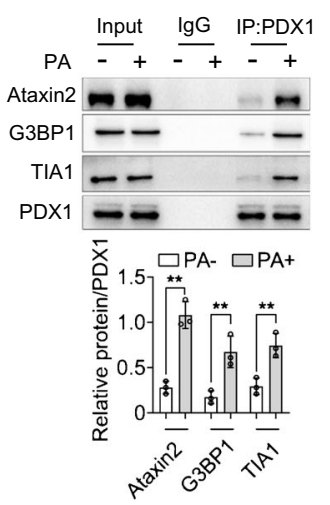

\section{f}

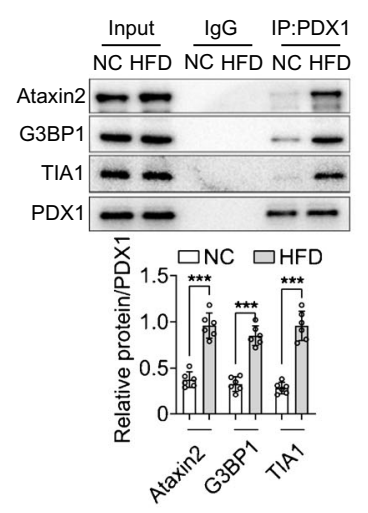

was enriched in the nucleus and S-GFP was enriched in the cytoplasm. INS1 cells transfected with S-tdTomato or S-GFP expression plasmid were then treated with $0.4 \mathrm{mmol} / \mathrm{l} \mathrm{PA}$ for $16 \mathrm{~h}$. PA stress led to cytoplasmic mislocalisation of StdTomato (Fig. 1a) and nuclear mislocalisation of S-GFP (Fig. 1b), which suggests that PA disrupted both nuclear import and export. Conversely, high glucose $(33.3 \mathrm{mmol} / \mathrm{l})$ did not affect S-tdTomato (Fig. 1a) or S-GFP localisation (Fig. 1b). Given that nucleocytoplasmic transport disruption associated with SG formation [24], we checked whether PA stress induces SG formation. We immunostained INS1 cells for G3BP1 (Fig. 1a) and TIA1 (ESM Fig. 2a), the core proteins of SG, and ataxin2 (ESM Fig. 2b), a modulator of SG formation [19]. We found that chronic PA stress caused SG assembly. We used immunoblotting to further confirm that fatty acids induced SG assembly both in vitro and in vivo. The P18000 fraction that contains SGs was separated from the WCL of INS1 cells or human islets, and then subjected to immunoblotting. We found that SG formation dramatically increased after $\mathrm{NaAsO}_{2}$ treatment, which is commonly 
Fig. 3 Suppression of SG formation by an inhibitor restored pancreatic function. (a) INS1 cells were treated with $\mathrm{NaAsO}_{2}$ $(0.5 \mathrm{mmol} / \mathrm{l})$ for $0.5 \mathrm{~h}$, or with PA $(0.4 \mathrm{mmol} / \mathrm{l})$ or glucose (33.3 mmol/l) for $16 \mathrm{~h}, \mathrm{WCL}$ were collected and subjected to western blot analysis for EIF $2 \alpha$ phosphorylation. (b, c) INS1 cells were treated with PA $(0.4 \mathrm{mmol} /$ $1)$, with or without ISRIB

$(2 \mu \mathrm{mol} / \mathrm{l})$ for $16 \mathrm{~h}$. Western blot analysis for EIF $2 \alpha$

phosphorylation in WCL (b), and ataxin2, G3BP1, TIA1 and PDX1 in the subcellular fractions (c). (d) INS1 cells were treated as described in (b), fixed and stained for G3BP1 (red) and DAPI (blue). Scale bar, $10 \mu \mathrm{m}$. (e) After PA treatment $(0.4 \mathrm{mmol} / \mathrm{l})$ with or without ISRIB $(2 \mu \mathrm{mol} / \mathrm{l})$ for $16 \mathrm{~h}$, nuclear and cytosolic fractions were prepared by using an NE-PER kit. PDX1 was detected by immunoblotting. PCNA and $\beta$-actin were used as loading controls for the nucleus and cytosol, respectively. (f) GSIS assay was performed after PA treatment in the presence/ absence of ISRIB, and then insulin levels in the KRBH buffer were determined by ELISA. Data are presented as mean $\pm \mathrm{SD}$.

${ }^{*} p<0.05, * * p<0.01$,

$* * * p<0.001 .(\mathbf{a}-\mathbf{c}, \mathbf{e}) n=3 ;(\mathbf{d})$ $n=21$; (f) $n=6$. Ctrl, control; P18000, pellet from $18,000 \times g$; PCNA, proliferating cell nuclear antigen; $S$, supernatant after $18,000 \times g ;$ SG/W, SGs/whole area a

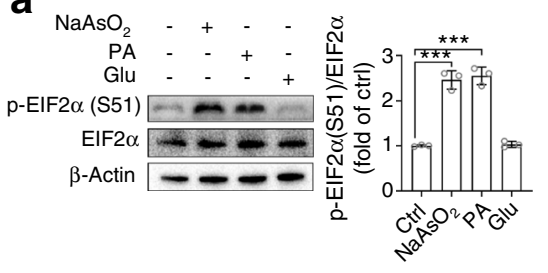

b

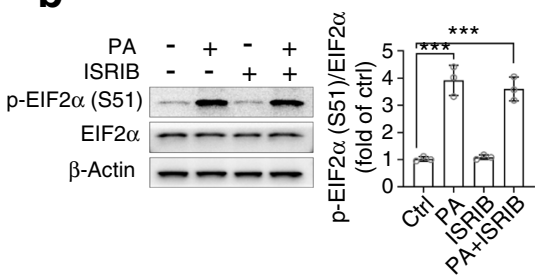

C
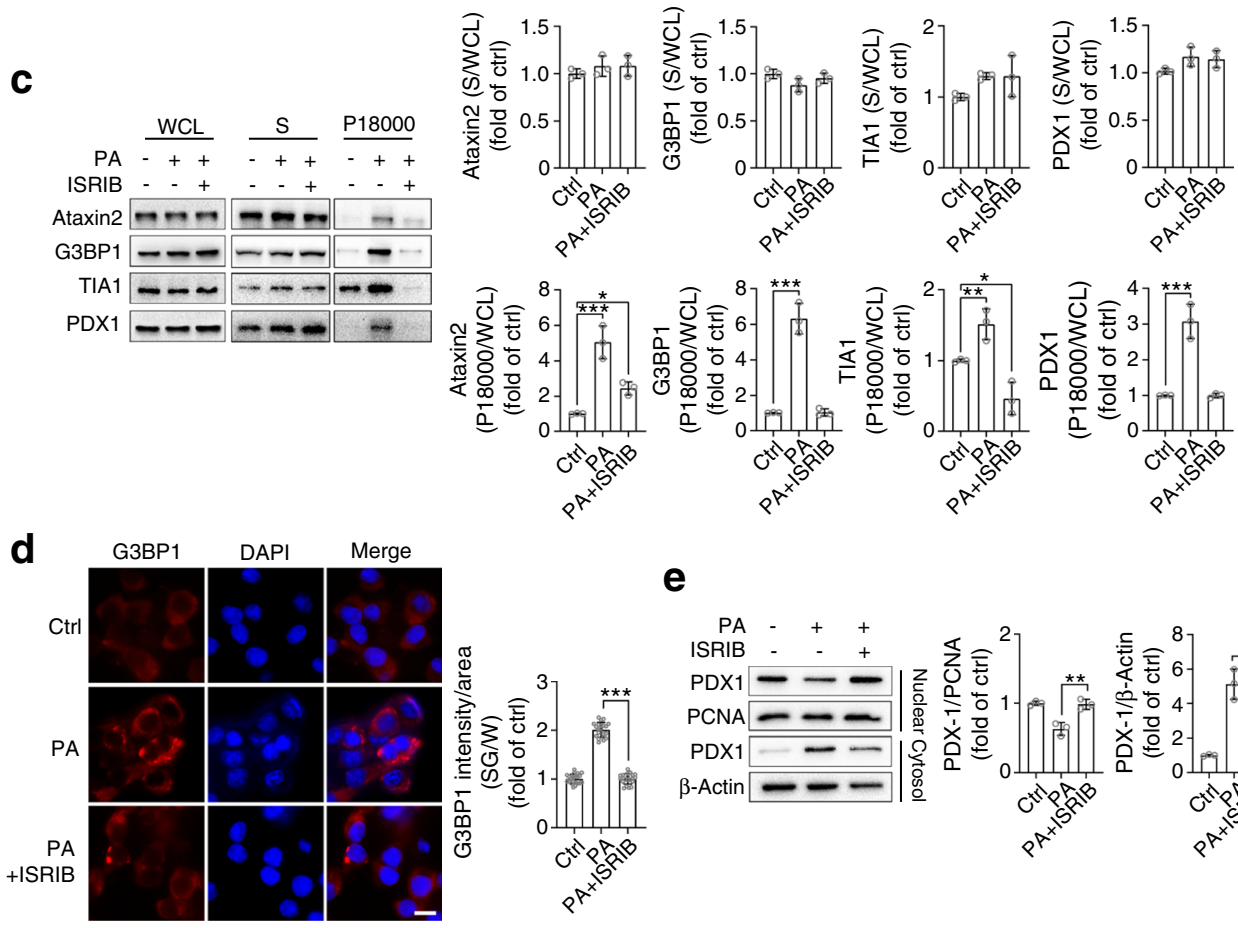

e
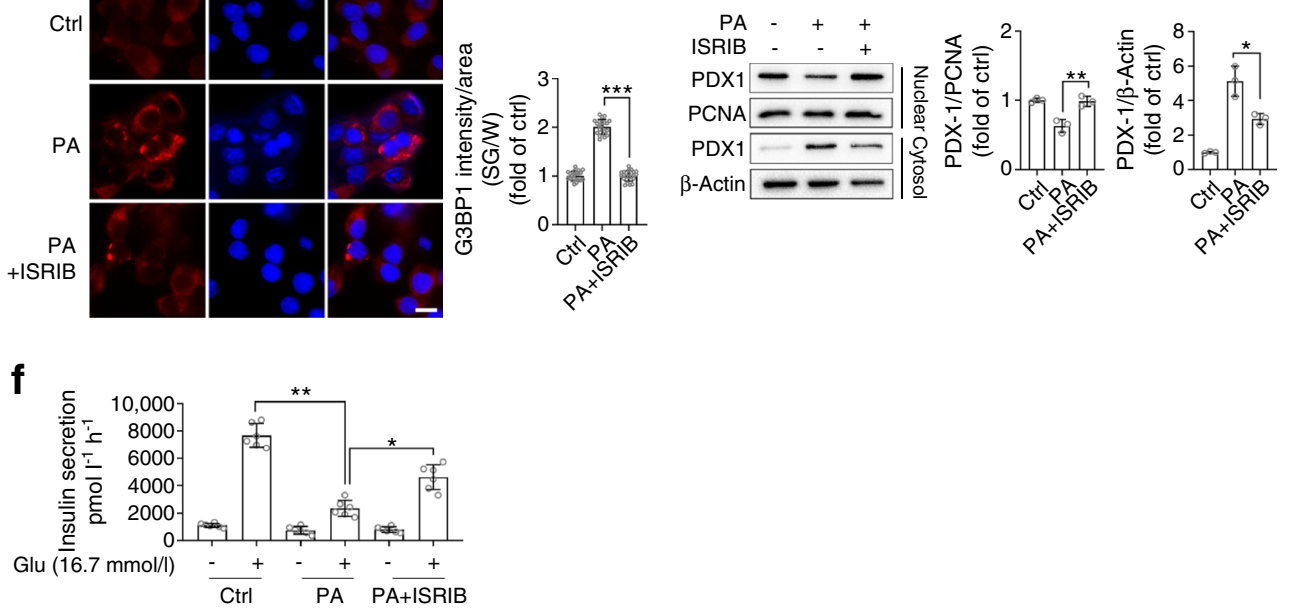

used to induce SGs, or PA treatment, as indicated by increased ataxin2, G3BP1 and TIA1 in the P18000 fraction (Fig. 1c). Increased SG formation was also observed in human islets after PA treatment (Fig. 1d). Thus, we identified PA as an endogenous stressor that disrupts nucleocytoplasmic transport and induces SG formation.

\section{Both PDX1 and nucleocytoplasmic transport factors are} sequestered in SGs To understand the relationship between SG formation and SFA-induced beta cell dysfunction, we explored the proteins in SGs that interact with G3BP1. SG fractions from INS1 cells treated with BSA or PA were further affinity purified by G3BP1 immunoprecipitation, and then the proteins that directly and indirectly interact with G3BP1 were pulled down and profiled by quantitative mass spectrometry. Proteins representing peptides with more spectral counts $(\geq 4)$ than the BSA control group are listed in ESM Table 1 and were subjected to further analysis.

Next, a Gene Ontology (GO) index-based function classification of the identified proteins was performed. Two hundred and five identified proteins were categorised according to molecular function (Fig. 2a, ESM Table 2), biological process (ESM Table 3), cellular component (ESM Table 4) and Kyoto Encyclopedia of Genes and Genomes (KEGG) pathway analyses (ESM Table 5). Twelve proteins were listed in the chromatin binding term, which included PDX1 (Fig. 2a, ESM Table 2). After $16 \mathrm{~h}$ PA treatment, PDX1 was observed in the cytoplasm and localised with the SG marker TIA1 (Fig. $2 b)$. Furthermore, immunoblotting showed that, compared with non-stressed cells, PDX1 was enriched in the sediment fraction containing SGs (P18000) of PA-stressed INS1 cells in a time-depend manner (Fig. 2c). The same results were also 

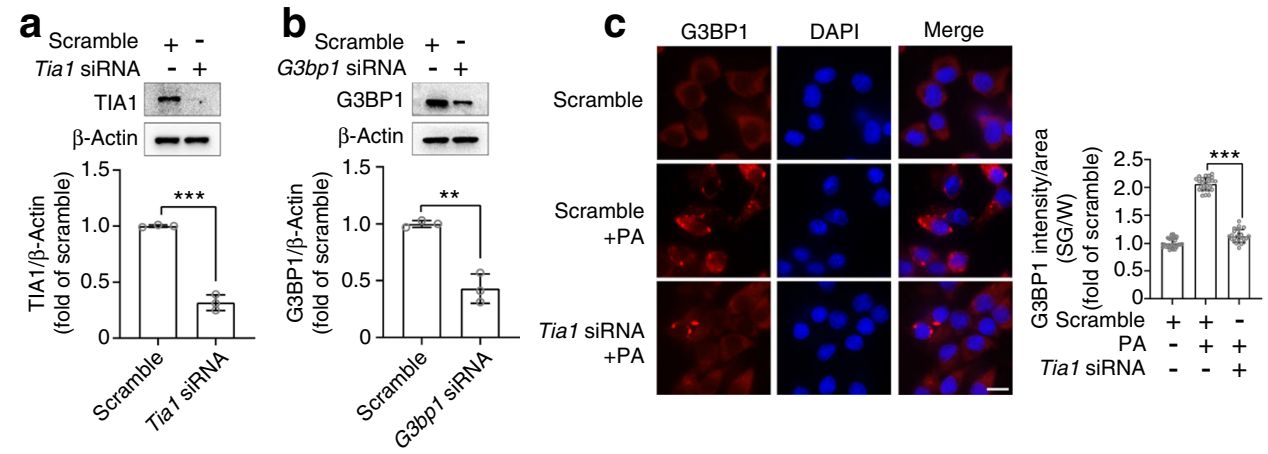

e Scramble ++-G3bp1 SiRNA - - + Tia1 SiRNA - - $\mathrm{PA}-+++$ $\begin{array}{lll}\text { PDX1 } & -\ldots-0 \\ \text { PCNA } & \text { Nuclear }\end{array}$ PDX1 $-1-2$ Cytosol $\beta$-Actin $-\ldots-1$ Cytoso

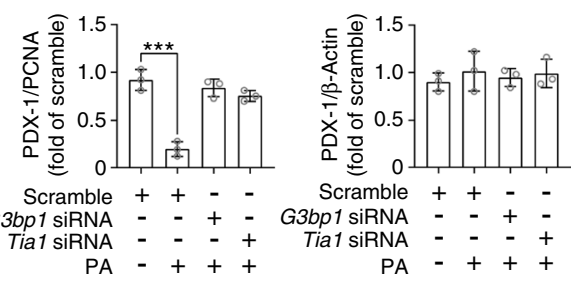

for $16 \mathrm{~h}$. Subcellular fractions (d) or nucleus and cytosol (e) samples were prepared for analysis of the indicated proteins. (f) GSIS from INS1 cells was tested after treatment as mentioned above. The insulin levels in the KRBH buffer were determined by ELISA. Data are presented as mean \pm SD. $* p<0.05, * * p<0.01, * * * p<0.001$. (a, b, d, e) $n=3 ;(\mathbf{c}) n=26$; (f) $n=6$. Ctrl, control; Glu, glucose; P18000, pellet from $18,000 \times g ; \mathrm{S}$, supernatant after $18,000 \times g$; SG/W, SGs /whole area; WCL, whole cell lysate

previous studies, PA treatment also induced mislocalisation of RAN from nucleus to the cytoplasm and, more specifically, enriched it in SGs, as indicated by the G3BP1-positive puncta (ESM Fig. 3a). Moreover, transport factors importin $\alpha 6$ and exportin1 were localised to SGs in INS1 cells (ESM Fig. 3b) and in human islets challenged by PA (ESM Fig. 3c). The recruitment of these transport factors to SGs is consistent with the impairment of the nucleocytoplasmic transport.

Inhibition of SG formation rescues PA-induced beta cell dysfunction Phosphorylation of EIF $2 \alpha$ is a key driver of SG formation [33]. As shown in Fig. 3, the EIF2 $\alpha$ phosphorylation levels in INS1 cells were increased after $\mathrm{NaAsO}_{2}$ or PA treatment. Conversely, high glucose did not induce EIF $2 \alpha$ phosphorylation (Fig. 3a). ISRIB is a small molecular inhibitor that solely inhibits cellular events downstream of EIF $2 \alpha$ phosphorylation [34], and hence blocks phospho-EIF2 $\alpha$ dependent SGs induction selectively $[24,35]$. We found that ISRIB could also inhibit PA-induced SG formation (Fig. 3c,d) nucleocytoplasmic transport failure [24]. Consistent with 
Fig. 5 SFA-induced PDX1 retention in SGs and pancreatic dysfunction depend on PI3K/Akt pathway. (a) INS1 cells were treated with PA $(0.4 \mathrm{mmol} / \mathrm{l})$ for the indicated time. Cells were lysed and the levels of the indicated proteins were determined. (b-d) INS1 cells were treated with PA $(0.4 \mathrm{mmol} / \mathrm{l})$ for $16 \mathrm{~h}$ with or without buparlisib $(1 \mu \mathrm{mol} / \mathrm{l})$, and then WCL (b), subcellular fraction (c) or nucleus and cytosol protein (d) samples were prepared for analysis of the indicated proteins. (e) GSIS from INS1 cells was tested after treatment as mentioned above and the insulin levels in the KRBH buffer were determined by ELISA. (a-d) $n=3 ;$ (e) $n=6$. Data are presented as mean $\pm \mathrm{SD}$. ${ }^{*} p<0.05, * * p<0.01$,

$* * * p<0.001$. Bupar, buparlisib; Ctrl, control; Glu, glucose; P18000, pellet from $18,000 \times g$; $\mathrm{S}$, supernatant after $18,000 \times g$; WCL, whole cell lysate
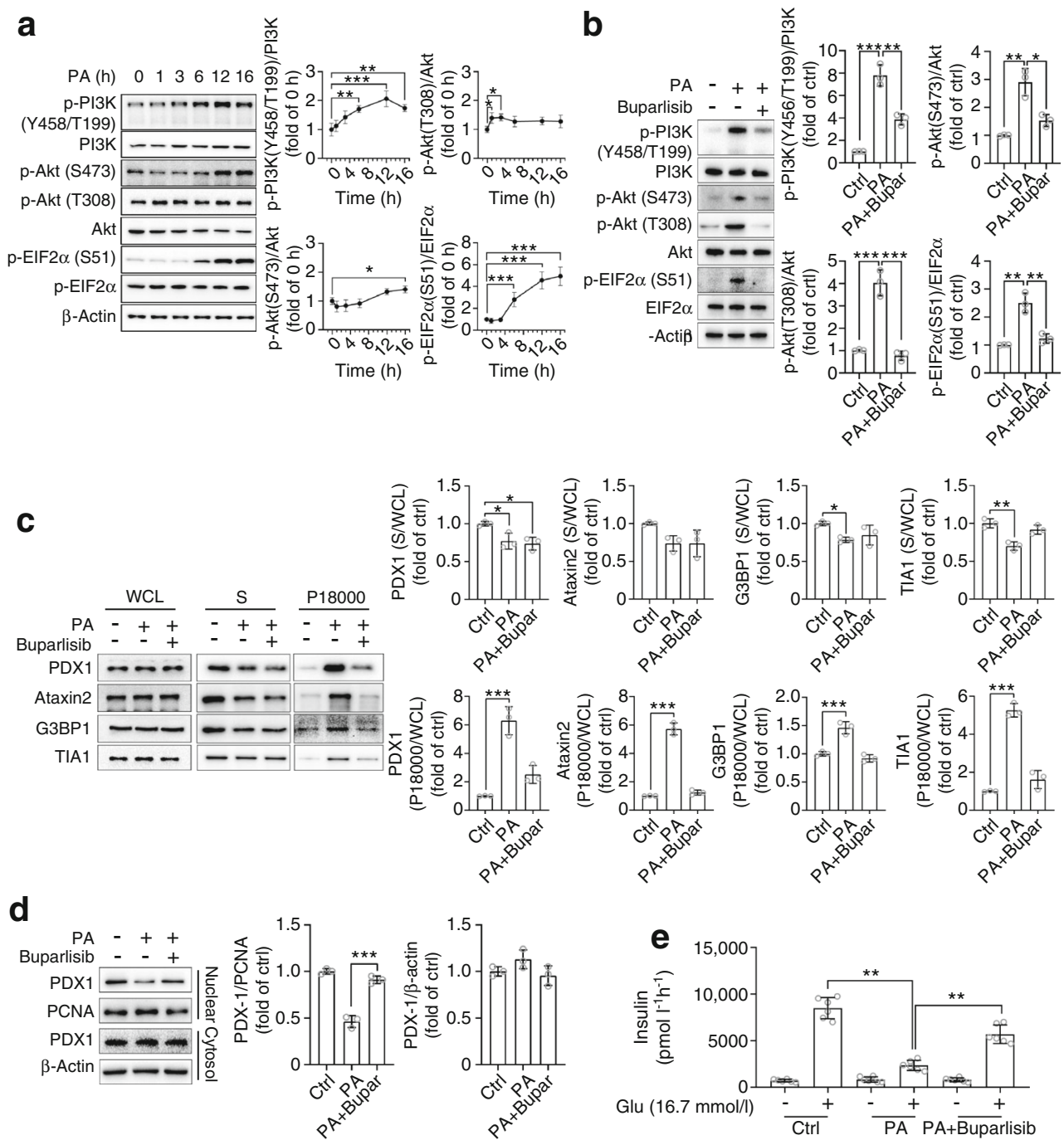

without affecting EIF $2 \alpha$ phosphorylation (Fig. 3b). Treatment with ISRIB effectively ameliorates PA-induced PDX1 mislocalisation (Fig. 3e). Furthermore, ISRIB enhanced GSIS under PA stress (Fig. 3f).

Next, we knocked down G3bpl or Tial using siRNAs (Fig. 4a,b) to prevent SG formation in INS1 cells (Fig. 4c), and observed that PDX1 was released from SGs (Fig. 4d) and successfully transported into the nucleus again (Fig. 4e). With PDX1 function restored, GSIS was also enhanced even in the presence of PA (Fig. 4f). Taken together, our data suggest that PA-induced SG formation indeed impairs pancreatic beta cell function.

PI3K is involved in PA-induced SG formation We next asked which upstream signal activates EIF2 $\alpha$ upon PA stress in islet beta cells. Previously, it has been shown that the phosphoinositide 3-kinases (PI3K) were activated under stress to transduce stress signals to Akt and induce SGs assembly [36]. As shown in Fig. 5a, the PI3K phosphorylation level was increased under PA stress in a time-dependent manner.
However, the Akt phosphorylation level was only slightly increased. The phosphorylation level of EIF $2 \alpha$ was significantly increased after PA treatment for $6 \mathrm{~h}$, and further enhanced with time. Conversely, the PI3K inhibitor, buparlisib, effectively suppressed the PA-induced phosphorylation of PI3K, Akt and EIF2 $\alpha$ (Fig. 5b). Buparlisib also suppressed the PA-induced SG formation, and thus PDX1 was released back into the soluble cytoplasm fraction (Fig. 5c). The released PDX1 was successfully transported into the nucleus (Fig. 5d) and improved GSIS in the presence of PA (Fig. 5e). These data suggest that disrupting SG formation clearly improves beta cell function.

In vivo inhibition of SG assembly ameliorates HFD-induced beta cell dysfunction To study the in vivo role of SG formation in pancreatic function, Tial ${ }^{f / f}$ mice were crossed with Ins2Cre mice to generate beta cell-specific Tial-knockout mice (ESM Fig. 1). BetaTIA1-KO mice were viable, fertile and indistinguishable from the WT littermates. We confirmed the pancreatic beta cell-specific ablation of TIA1 by 
Fig. 6 Disruption of SG formation in vivo restores pancreatic function in HFD-fed diabetic mice. Eight-week old male betaTIA1-KO mice and their WT littermates, weighing 22-24 g, were randomly grouped $(n=6)$. WT mice and betaTIA1$\mathrm{KO}$ mice were fed normal chow or HFD for 10 weeks. (a) TIA1 protein levels in pancreatic tissues of WT or betaTIA1-KO mice. (b) Food intake. (c) Weight gain. (d) Pancreatic tissues were fixed and stained for G3BP1 (green) and DAPI (blue). Quantitative analysis of the distribution of SGs in tissues is shown on the right. Scale bar, $25 \mu \mathrm{m}$. (e) For the IPGTT assay, animals were i.p. injected with glucose after $16 \mathrm{~h}$ starvation, and then blood glucose levels were recorded at $0,15,30$, 60 and $120 \mathrm{~min}$, and the AUC is shown to the right. (f) The nuclear and cytosolic protein samples from the indicated animal pancreatic tissues were prepared for analysis of the indicated proteins, and quantification of protein levels is shown to the right. (g) Pancreatic insulin content. (h) Islets from WT and betaTIA1-KO mice fed with NC or HFD were isolated and subjected to the GSIS assay. (a-c e-h) $n=6$; (d) $n=18$. Data are presented as mean $\pm \mathrm{SD}$. $* p<0.05, * * p<0.01$, $* * * p<0.001$. NC, normal chow; $\mathrm{P} 18000$, pellet from $18,000 \times g$ $\mathrm{S}$, supernatant after $18,000 \times g$; $\mathrm{SG} / \mathrm{W}, \mathrm{SG}$ /whole area a

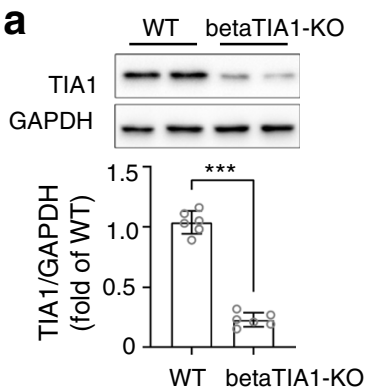

b

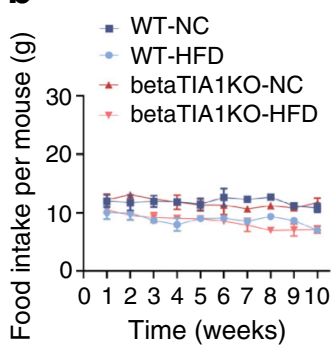

C

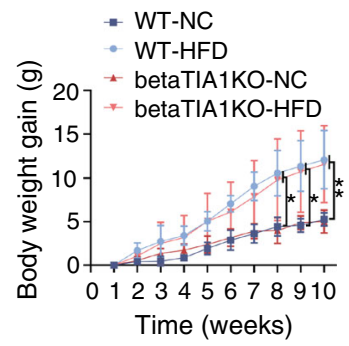

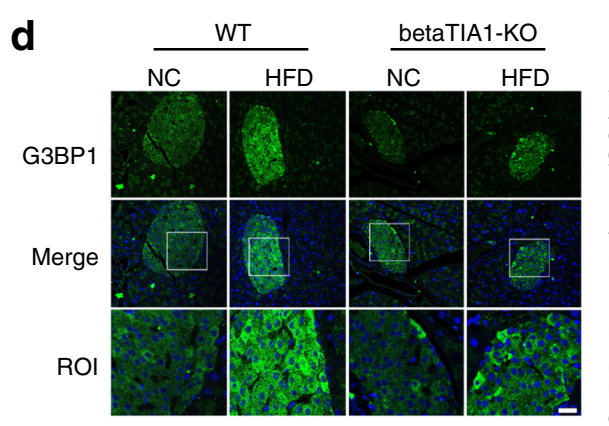

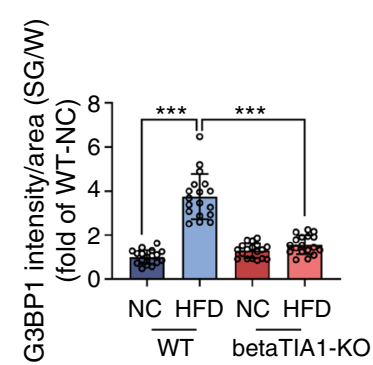

e - WT-NC - betaTIA1-KO-NC

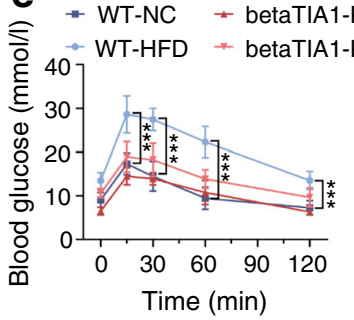

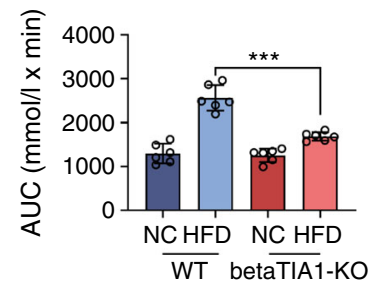

$\mathbf{f}$
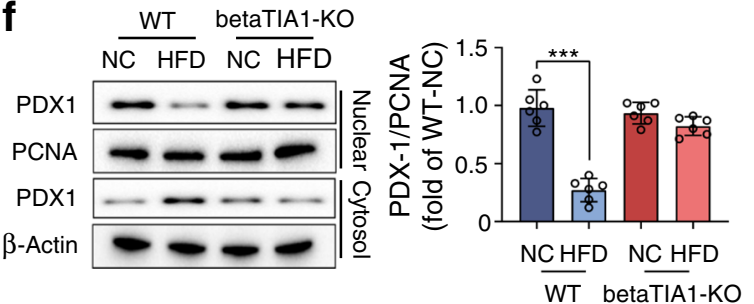

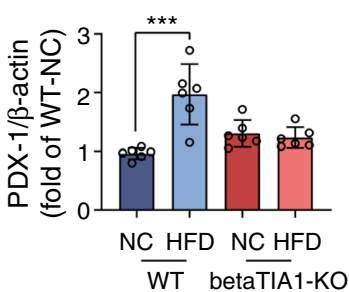

$\overline{\mathrm{WT}}$ betaTIA $1-\mathrm{KO}$
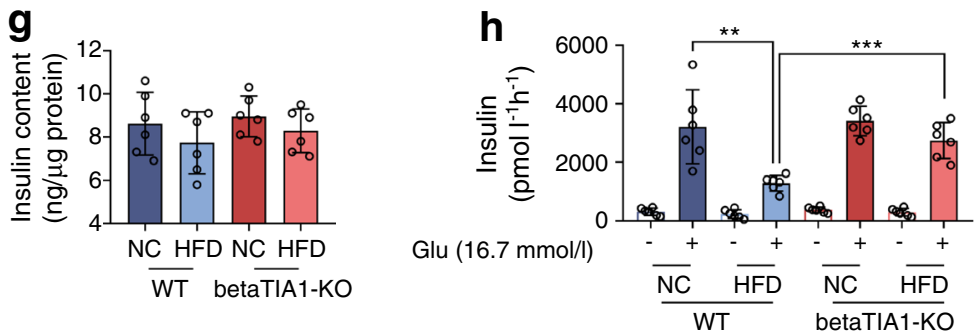

immunoblotting analysis of pancreatic tissue isolated from betaTIA1-KO and WT mice (Fig. 6a). The 8-week old betaTIA1-KO mice were fed with normal chow or HFD for 10 weeks. No difference in food intake was observed between the four groups (Fig. 6b). Tial deletion did not affect HFDinduced body weight gain (Fig. 6c). After the IPGTT, animals were euthanised and pancreatic tissues were collected for further study. Tial deletion effectively suppressed SG formation in the pancreas of HFD-fed mice (Fig. 6d). Glucose tolerance was improved in betaTIA1-KO mice compared with WT mice on HFD (Fig. 6e), possibly because of the restoration of the PDX1 nuclear localisation (Fig. 6f). The insulin content of pancreas tissue from different groups was not significantly changed (Fig. 6g). We then carried out tests on isolated islets. 
Fig. 7 Schematic representation of SG regulation of PDX1 under SFA stress. Prolonged exposure of islet beta cells to SFAs induces SG formation in a PI3K/EIF2 $\alpha$ dependent manner. Both nucleocytoplasmic transport factors and PDX1 are sequestered in SGs in the presence of SFAs, thereby inhibiting PDX1 translocation into the nucleus and insulin secretion

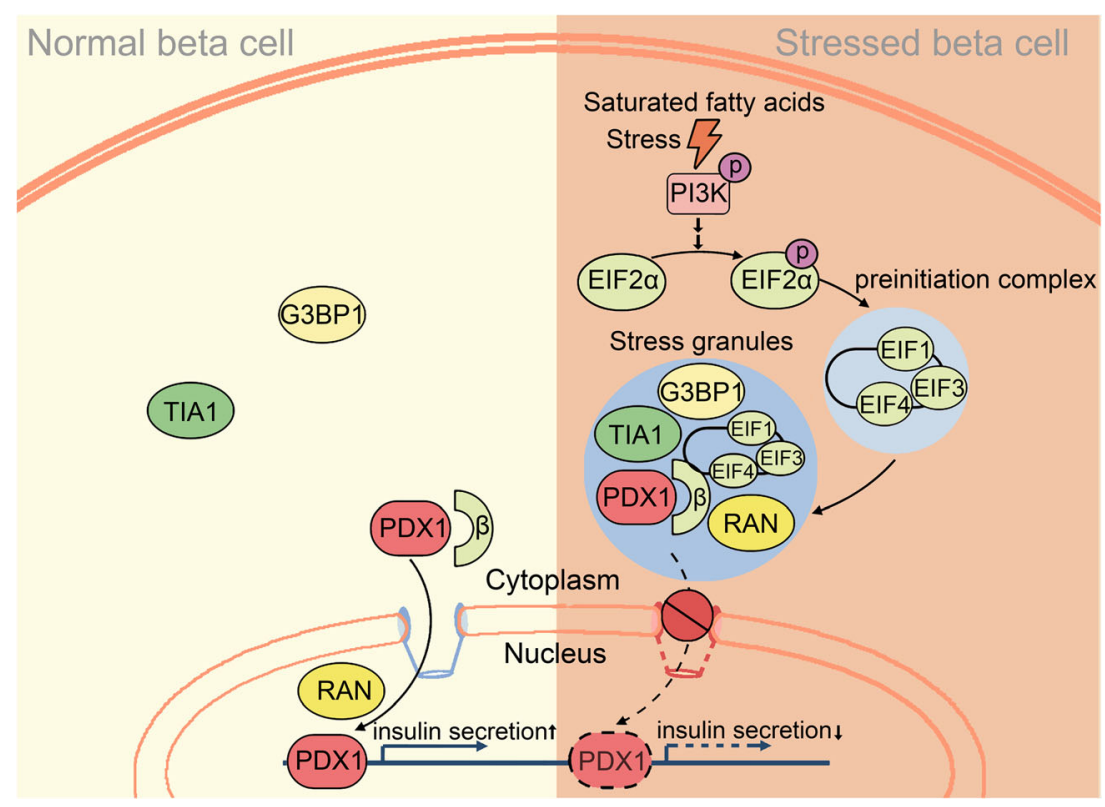

As shown in Fig. 6h, the GSIS from islets of HFD-fed WT mice was impaired, whereas it was significantly recovered in islets of betaTIA1-KO mice. Taken together, our data suggest that inhibiting SG assembly ameliorates beta cell dysfunction in an HFD-induced type 2 diabetes mouse model by restoring PDX1 localisation and activity.

\section{Discussion}

Pancreatic beta cell dysfunction with defects in GSIS is a diagnostic determinant of type 2 diabetes. PDX1 is the major regulator of glucose-stimulated insulin transcription and secretion [13]. Inactivation of PDX1 was observed under stress conditions and was suggested to be responsible for beta cell dysfunction and the onset of type 2 diabetes [37]. PDX1 mislocalisation in beta cells under stress conditions has been observed in earlier studies, but the molecular mechanisms remained largely uncharacterised. Herein, we show that PA disrupted the PDX1 nucleocytoplasmic transport and sequestrated it in SGs, thereby hampering PDX1 transcriptional activity. These data provide a new link between SFAs and the impaired pancreatic beta cell function and the development of diabetes (Fig. 7).

SG formation is a transient, reversible event necessary for a cytoprotective response to an acute stress; once the stress is removed the SGs will dispel within a few hours [33]. However, the hyperactive response to chronic stresses in disease leads to abnormal stable SG formation that is thought to contribute to the pathological process [38]. Our results show that stable SGs existed persistently in INS1 cells under prolonged PA treatment (Fig. 2c, ESM Fig. 3b) along with impaired GSIS (Fig. 3f), indicating a close relationship between SG assembly and chronic PA stress-induced pancreatic beta cell dysfunction. Moreover, the beta cell's high capacity for nutrient sensing necessitates reduced protection from nutrient toxicity [39], which may relate to increased predisposition to forming stable SGs. The temporal order of nucleocytoplasmic transport disruption and PDX1 sequestration is unclear and will be further studied. Results of the subcellular localisation of other important transcription factors, such as MafA and BETA2, in beta cells under stress are inconsistent in previous studies [10, 37]. Although the direct interactions between SGs and insulin transcription factors other than PDX1 is not observed in our study, we think the effects of SGs on nucleocytoplasmic transport (Fig. 1) play key roles in the mislocalisation and dysfunction of other transcription factors under stress, which will be further studied.

SG condensation is mediated by the accumulation of stalled (preinitiation) translation complexes (PICs) [40]. Various stresses induce EIF $2 \alpha$ phosphorylation by activating EIF2 $\alpha$ kinases, such as protein kinase $\mathrm{R}$ (PKR), general control nonderepressible 2 (GCN2), PKR-like ER kinase (PERK) and heme-regulated kinase (HRI), and promote PIC formation. Accumulation of 48S PICs that lack early initiation factors EIF2 and EIF5 further induces SG assembly [40]. ER stress and EIF $2 \alpha$ phosphorylation have been considered as key events during beta cell dysfunction [41], but the downstream events are not fully understood. In the present study, we report that chronic SFA stress induced SG formation in an EIF2 $\alpha$-dependent manner.

Preventing SG formation by small molecular inhibitors such as GSK2606414, ISRIB, or by genetic deletion of Ataxin2 or Tial, or antisense oligonucleotides targeting Ataxin2, has been shown to suppress toxicity in yeast and animal models of ALS and tauopathies [24, 42-44]. In our study, suppressing SG assembly using the inhibitors ISRIB and buparlisib, or by 
depleting TIA1, effectively attenuated PA- and HFD-induced PDX1 mislocalisation and beta cell dysfunction. These results raise the possibility of targeting SGs in beta cells for the treatment of type 2 diabetes. TIA1 belongs to a family of U-rich element mRNA-binding proteins ubiquitously expressed and conserved in metazoans. TIA1 and TIA1 cytotoxic granule associated RNA binding protein like 1 (TIAL1) are two members of this family in humans. TIA1 is responsible for nuclear and cytosolic RNA metabolic processes [45]. TIA1 depletion promotes cell proliferation [46] and tumour invasion [47]. Both TIA1 and TIAL1 link EIF2 $\alpha$ phosphorylation to the assembly of mammalian SGs [33]. Tial knockout prevented SG formation and inhibited tau pathophysiology in a mouse model [48]. It is interesting that Tial knockout has a significant effect on mRNAs encoding lipid homeostasis factors in the brain [49]. The potential effect of Tial genetic deletion on lipid metabolism in the pancreas requires further study.

Modulated EIF2 $\alpha$ phosphorylation rescued SG-induced toxicity in an animal model [42]. Active PI3K has been reported to be the main driver of SGs [36]. Herein, we observed significant PI3K activation and EIF2 $\alpha$ phosphorylation in INS1 cells under PA stress. Inhibiting PI3K by buparlisib effectively prevented SG formation induced by PA, and improved GSIS. PI3K has been shown to regulate EIF $2 \alpha$ phosphorylation in nerve cells [50]. Blockade of PI3K was found to inhibit fungus- or bleomycin-induced ER stress and EIF $2 \alpha$ phosphorylation $[51,52]$. Under conditions of PI3K hyperactivity, the ER is subjected to a high load of protein generation and is subsequently disturbed [53]. It is known that ER stress play key roles in SG formation [54] and in SFAinduced beta cell impairment [55]. Whether ER stress is directly involved in PI3K-induced EIF2 $\alpha$ phosphorylation under PA stress should be determined in further study. Our study provides new insight into the pathological effects of PI3K under PA stress. Buparlisib is an oral pan-PI3K inhibitor being tested in clinical trials for solid tumours and breast cancer. Both sporadically increased blood insulin levels and hyperglycaemia were observed during clinical studies on buparlisib [56]. Hence, the in vivo effects of buparlisib during type 2 diabetes treatment require further research.

Supplementary Information The online version contains peer-reviewed but unedited supplementary material available at https://doi.org/10.1007/ s00125-021-05389-4.

Acknowledgements The S-GFP plasmid was a kind gift from F. U. Hartl (Department of Cellular Biochemistry, the Max Planck Institute of Biochemistry, Germany). We thank W. Liu (Institute of Translational Medicine, Nanjing Medical University, China) for valuable suggestions. We thank J. Zhang (The Second Xiangya Hospital of Central South University, China) for technical support with INS1 cell culture.

Data availability The datasets generated during and/or analysed during the current study are available from the corresponding author on reasonable request.
Funding This work was supported by the National Key R\&D Program of China (grant no. 2016YFC1305000), the National Natural Science Foundation of China (grant no. 81803750, 81770778), the Key Medical Talents Project of Jiangsu Province (grant no. ZDRCA2016088), the Key Project of Jiangsu Science and Technology Plan (grant no. BE2017738) and the Jiangsu Province Innovative and Entrepreneurial Team Grant. This project was also supported by the Project Program of State Key Laboratory of Natural Medicines, China Pharmaceutical University (SKLNMZZCX201820) and the "Double First-Class" University Project (CPU2018GF04).

Authors' relationships and activities The authors declare that there are no relationships or activities that might bias, or be perceived to bias, their work.

Contribution statement $\mathrm{YuL}, \mathrm{CQ}$ and $\mathrm{MuZ}$ conceived and designed the work. MuZ, CQ and CJY performed the cell experiments and acquired data. XJX and HMC performed the animal experiments and acquired data. MengZ, LQ, YanL and RG contributed to sample preparation and data acquisition. MuZ and CQ interpreted the data and wrote the manuscript. CJY, XJX, HMC, MengZ, LQ, YanL and RG made contributions to revising the article for important intellectual content. YuL revised the manuscript critically. All authors gave final approval of the version to be published. YuL is the guarantor of this work, has full access to all of the data in the study and takes responsibility for the integrity of the data and the accuracy of the data analysis.

\section{References}

1. Hou J, Li Z, Zhong W et al (2017) Temporal Transcriptomic and proteomic landscapes of deteriorating pancreatic islets in type 2 diabetic rats. Diabetes 66(8):2188-2200. https://doi.org/10.2337/ db16-1305

2. Barnes AS (2011) The epidemic of obesity and diabetes: Trends and treatments. Tex Heart Inst J 38(2):142-144

3. Robertson RP, Harmon J, Tran POT, Poitout V (2004) Beta-cell glucose toxicity, lipotoxicity, and chronic oxidative stress in type 2 diabetes. Diabetes 53(Suppl 1):S119-S124

4. Oh YS, Bae GD, Baek DJ, Park E-Y, Jun H-S (2018) Fatty acidinduced lipotoxicity in pancreatic Beta-cells during development of type 2 diabetes. Front Endocrinol 9:384

5. Newsholme P, Keane D, Welters HJ, Morgan NG (2007) Life and death decisions of the pancreatic beta-cell: The role of fatty acids. Clin Sci 112(1):27-42. https://doi.org/10.1042/CS20060115

6. López S, Bermúdez B, Abia R, Muriana FJG (2010) The influence of major dietary fatty acids on insulin secretion and action. Curr Opin Lipidol 21(1):15-20. https://doi.org/10.1097/MOL. 0b013e3283346d39

7. Itami N, Shirasuna K, Kuwayama T, Iwata H (2018) Palmitic acid induces ceramide accumulation, mitochondrial protein hyperacetylation, and mitochondrial dysfunction in porcine oocytes. Biol Reprod 98(5):644-653. https://doi.org/10.1093/ biolre/ioy023

8. Yu G, Luo H, Zhang N et al (2019) Loss of p53 Sensitizes Cells to Palmitic Acid-Induced Apoptosis by Reactive Oxygen Species Accumulation. Int J Mol Sci 20(24). https://doi.org/10.3390/ ijms 20246268

9. Borradaile NM, Han X, Harp JD, Gale SE, Ory DS, Schaffer JE (2006) Disruption of endoplasmic reticulum structure and integrity in lipotoxic cell death. J Lipid Res 47(12):2726-2737. https://doi. org/10.1194/jlr.M600299-JLR200 
10. Hagman DK, Hays LB, Parazzoli SD, Poitout V (2005) Palmitate inhibits insulin gene expression by altering PDX-1 nuclear localization and reducing MafA expression in isolated rat islets of Langerhans. J Biol Chem 280(37):32413-32418. https://doi.org/ 10.1074/jbc.M506000200

11. Ritz-Laser B, Meda P, Constant I et al (1999) Glucose-induced preproinsulin gene expression is inhibited by the free fatty acid palmitate. Endocrinology 140(9):4005-4014. https://doi.org/10. 1210/endo.140.9.6953

12. Jonsson J, Carlsson L, Edlund T, Edlund H (1994) Insulinpromoter-factor 1 is required for pancreas development in mice. Nature 371(6498):606-609. https://doi.org/10.1038/371606a0

13. Brissova M, Shiota M, Nicholson WE et al (2002) Reduction in pancreatic transcription factor PDX-1 impairs glucose-stimulated insulin secretion. J Biol Chem 277(13):11225-11232. https://doi. org/10.1074/jbc.M111272200

14. Stoffers DA, Ferrer J, Clarke WL, Habener JF (1997) Early-onset type-II diabetes mellitus (MODY4) linked to IPF1. Nat Genet 17(2):138-139. https://doi.org/10.1038/ng1097-138

15. Stoffers DA, Stanojevic V, Habener JF (1998) Insulin promoter factor-1 gene mutation linked to early-onset type 2 diabetes mellitus directs expression of a dominant negative isoprotein. J Clin Invest 102(1):232-241. https://doi.org/10.1172/JCI2242

16. Hagman DK, Latour MG, Chakrabarti SK et al (2008) Cyclical and alternating infusions of glucose and intralipid in rats inhibit insulin gene expression and Pdx-1 binding in islets. Diabetes 57(2):424431. https://doi.org/10.2337/db07-1285

17. Reimer MK, Ahrén B (2002) Altered beta-cell distribution of pdx-1 and GLUT-2 after a short-term challenge with a high-fat diet in C57BL/6J mice. Diabetes 51(Suppl 1):S138-S143

18. Spector DL (2006) SnapShot: Cellular bodies. Cell 127(5):1071. https://doi.org/10.1016/j.cell.2006.11.026

19. Protter DSW, Parker R (2016) Principles and properties of stress granules. Trends Cell Biol 26(9):668-679. https://doi.org/10.1016/ j.tcb.2016.05.004

20. Anderson P, Kedersha N (2002) Stressful initiations. J Cell Sci 115(Pt 16):3227-3234

21. Li YR, King OD, Shorter J, Gitler AD (2013) Stress granules as crucibles of ALS pathogenesis. J Cell Biol 201(3):361-372. https:// doi.org/10.1083/jcb.201302044

22. Ramaswami M, Taylor JP, Parker R (2013) Altered ribostasis: RNA-protein granules in degenerative disorders. Cell 154(4):727736. https://doi.org/10.1016/j.cell.2013.07.038

23. Gao X, Jiang L, Gong Y et al (2019) Stress granule: A promising target for cancer treatment. Br J Pharmacol 176(23):4421-4433. https://doi.org/10.1111/bph.14790

24. Zhang K, Daigle JG, Cunningham KM et al (2018) Stress granule assembly disrupts Nucleocytoplasmic transport. Cell 173(4):958971 e917. https://doi.org/10.1016/j.cell.2018.03.025

25. Wang Y, Danielson KK, Ropski A et al (2013) Systematic analysis of donor and isolation factor's impact on human islet yield and size distribution. Cell Transplant 22(12):2323-2333. https://doi.org/10. 3727/096368912X662417

26. Yang CH, Mangiafico SP, Waibel M et al (2020) E2f8 and Dlg2 genes have independent effects on impaired insulin secretion associated with hyperglycaemia. Diabetologia 63(7):1333-1348. https://doi.org/10.1007/s00125-020-05137-0

27. Wan X-M, Zhang M, Zhang P et al (2016) Jiawei Erzhiwan improves menopausal metabolic syndrome by enhancing insulin secretion in pancreatic $\beta$ cells. Chin J Nat Med 14(11):823-834. https://doi.org/10.1016/S1875-5364(16)30099-1

28. Jain S, Wheeler JR, Walters RW, Agrawal A, Barsic A, Parker R (2016) ATPase-modulated stress granules contain a diverse proteome and substructure. Cell 164(3):487-498. https://doi.org/10. 1016/j.cell.2015.12.038
29. Zhang K, Donnelly CJ, Haeusler AR et al (2015) The C9orf72 repeat expansion disrupts nucleocytoplasmic transport. Nature 525(7567):56-61. https://doi.org/10.1038/nature14973

30. Morgan NG (2009) Fatty acids and beta-cell toxicity. Curr Opin Clin Nutr Metab Care 12(2):117-122. https://doi.org/10.1097/ MCO.0b013e328321e423

31. Woerner AC, Frottin F, Hornburg D et al (2016) Cytoplasmic protein aggregates interfere with nucleocytoplasmic transport of protein and RNA. Science 351(6269):173-176. https://doi.org/10. 1126/science.aad2033

32. Steggerda SM, Paschal BM (2002) Regulation of nuclear import and export by the GTPase ran. Int Rev Cytol 217:41-91

33. Kedersha NL, Gupta M, Li W, Miller I, Anderson P (1999) RNAbinding proteins TIA-1 and TIAR link the phosphorylation of eIF-2 alpha to the assembly of mammalian stress granules. J Cell Biol 147(7):1431-1442. https://doi.org/10.1083/jcb.147.7.1431

34. Sidrauski C, Acosta-Alvear D, Khoutorsky A et al (2013) Pharmacological brake-release of mRNA translation enhances cognitive memory. Elife 2:e00498. https://doi.org/10.7554/eLife. 00498

35. Sidrauski C, McGeachy AM, Ingolia NT, Walter P (2015) The small molecule ISRIB reverses the effects of eIF $2 \alpha$ phosphorylation on translation and stress granule assembly. eLife 4 . https://doi. org/10.7554/eLife.05033

36. Heberle AM, Razquin Navas P, Langelaar-Makkinje M et al (2019) The PI3K and MAPK/p38 pathways control stress granule assembly in a hierarchical manner. Life Sci Alliance 2(2). https://doi.org/ 10.26508/lsa.201800257

37. Guo $S$, Dai $C$, Guo $M$ et al (2013) Inactivation of specific $\beta$ cell transcription factors in type 2 diabetes. J Clin Invest 123(8):33053316. https://doi.org/10.1172/JCI65390

38. Ash PEA, Vanderweyde TE, Youmans KL, Apicco DJ, Wolozin B (2014) Pathological stress granules in Alzheimer's disease. Brain Res 1584:52-58. https://doi.org/10.1016/j.brainres.2014.05.052

39. Nolan CJ, Prentki M (2008) The islet beta-cell: Fuel responsive and vulnerable. Trends Endocrinol Metab 19(8):285-291. https://doi. org/10.1016/j.tem.2008.07.006

40. Panas MD, Ivanov P, Anderson P (2016) Mechanistic insights into mammalian stress granule dynamics. J Cell Biol 215(3):313-323. https://doi.org/10.1083/jcb.201609081

41. Cnop M, Toivonen S, Igoillo-Esteve M, Salpea P (2017) Endoplasmic reticulum stress and eIF2 $\alpha$ phosphorylation: The Achilles heel of pancreatic $\beta$ cells. Mol Metab 6(9):1024-1039. https://doi.org/10.1016/j.molmet.2017.06.001

42. Kim H-J, Raphael AR, LaDow ES et al (2014) Therapeutic modulation of eIF $2 \alpha$ phosphorylation rescues TDP-43 toxicity in amyotrophic lateral sclerosis disease models. Nat Genet 46(2):152-160. https://doi.org/10.1038/ng.2853

43. Elden AC, Kim H-J, Hart MP et al (2010) Ataxin-2 intermediatelength polyglutamine expansions are associated with increased risk for ALS. Nature 466(7310):1069-1075. https://doi.org/10.1038/ nature 09320

44. Apicco DJ, Ash PEA, Maziuk B et al (2018) Reducing the RNA binding protein TIA1 protects against tau-mediated neurodegeneration in vivo. Nat Neurosci 21(1):72-80. https://doi.org/10.1038/ s41593-017-0022-Z

45. Dember LM, Kim ND, Liu KQ, Anderson P (1996) Individual RNA recognition motifs of TIA-1 and TIAR have different RNA binding specificities. J Biol Chem 271(5):2783-2788. https://doi. org/10.1074/jbc.271.5.2783

46. Reyes R, Alcalde J, Izquierdo JM (2009) Depletion of T-cell intracellular antigen proteins promotes cell proliferation. Genome Biol 10(8):R87. https://doi.org/10.1186/gb-2009-10-8-r87

47. Izquierdo JM, Alcalde J, Carrascoso I, Reyes R, Ludeña MD (2011) Knockdown of $\mathrm{T}$-cell intracellular antigens triggers cell 
proliferation, invasion and tumour growth. Biochem J 435(2):337344. https://doi.org/10.1042/BJ20101030

48. Vanderweyde T, Apicco DJ, Youmans-Kidder K et al (2016) Interaction of tau with the RNA-binding protein TIA1 regulates tau pathophysiology and toxicity. Cell Rep 15(7):1455-1466. https://doi.org/10.1016/j.celrep.2016.04.045

49. Heck MV, Azizov M, Stehning T, Walter M, Kedersha N, Auburger G (2014) Dysregulated expression of lipid storage and membrane dynamics factors in Tia1 knockout mouse nervous tissue. Neurogenetics 15(2):135-144. https://doi.org/10.1007/ s10048-014-0397-x

50. Lewerenz J, Baxter P, Kassubek R et al (2014) Phosphoinositide 3kinases upregulate system $\mathrm{xc}(-)$ via eukaryotic initiation factor $2 \alpha$ and activating transcription factor 4 - a pathway active in glioblastomas and epilepsy. Antioxid Redox Signal 20(18):2907-2922. https://doi.org/10.1089/ars.2013.5455

51. Lee KS, Jeong JS, Kim SR et al (2016) Phosphoinositide 3-kinase- $\delta$ regulates fungus-induced allergic lung inflammation through endoplasmic reticulum stress. Thorax 71(1):52-63. https://doi.org/10. 1136/thoraxjnl-2015-207096

52. Hsu HS, Liu CC, Lin JH et al (2017) Involvement of ER stress, PI3K/AKT activation, and lung fibroblast proliferation in bleomycin-induced pulmonary fibrosis. Sci Rep 7(1):14272. https://doi.org/10.1038/s41598-017-14612-5

53. Kim HK, Lee GH, Bhattarai KR et al (2018) PI3K $\delta$ contributes to ER stress-associated asthma through ER-redox disturbances: The involvement of the RIDD-RIG-I-NF-KB axis. Exp Mol Med 50(2): e444. https://doi.org/10.1038/emm.2017.270

54. Backlund M, Paukku K, Kontula KK, Lehtonen JY (2016) Endoplasmic reticulum stress increases AT1R mRNA expression via TIA-1-dependent mechanism. Nucleic Acids Res 44(7):30953104. https://doi.org/10.1093/nar/gkv1368

55. Preston AM, Gurisik E, Bartley C, Laybutt DR, Biden TJ (2009) Reduced endoplasmic reticulum (ER)-to-Golgi protein trafficking contributes to ER stress in lipotoxic mouse beta cells by promoting protein overload. Diabetologia 52(11):2369-2373. https://doi.org/ 10.1007/s00125-009-1506-5

56. Ando Y, Inada-Inoue M, Mitsuma A et al (2014) Phase I doseescalation study of buparlisib (BKM120), an oral pan-class I PI3K inhibitor, in Japanese patients with advanced solid tumors. Cancer Sci 105(3):347-353. https://doi.org/10.1111/cas.12350

Publisher's note Springer Nature remains neutral with regard to jurisdictional claims in published maps and institutional affiliations. 